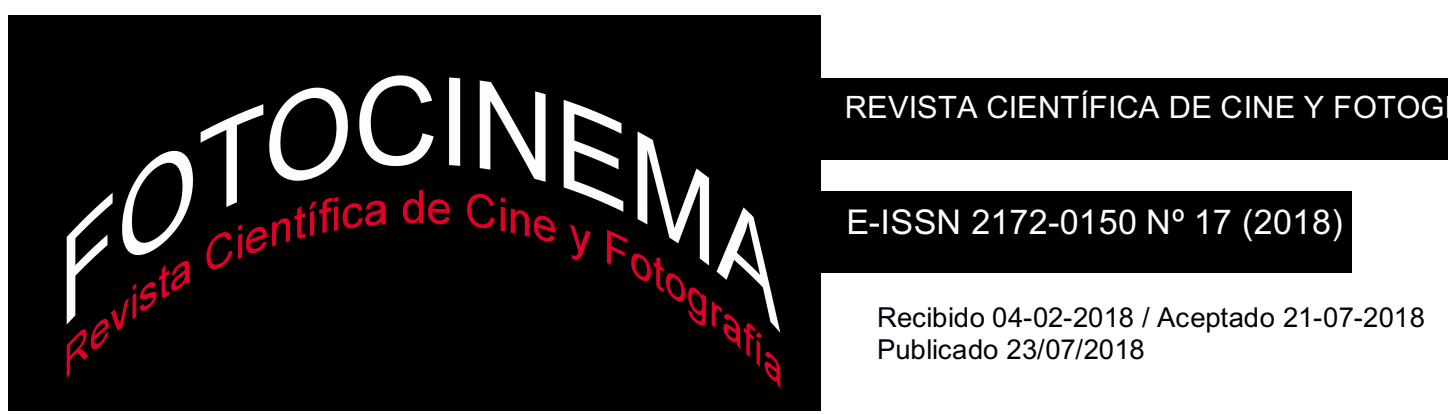

\title{
Un tipo de documento visual descuidado en España: la fotografía espiritista
}

\section{A kind of neglected visual document in Spain: the spiritualist photograpy}

\author{
Jordi Ardanuy \\ Universitat de Barcelona, España \\ jordi_ardanuy@ub.edu \\ Martí Flò Csefkó \\ Universitat de Barcelona, España \\ mflo@ub.edu
}

\section{Resumen:}

La llamada fotografía espiritista fue durante mucho tiempo un tipo de documento visual prácticamente olvidado por los historiadores, crítica y público en general. A nivel internacional, desde finales del siglo pasado diferentes estudios han reivindicado el interés de estas imágenes y el contexto cultural en el cual aparecen. Sin embargo, en España no se han realizado hasta ahora estudios equivalentes. En estas circunstancias este artículo pretende hacer una primera aportación a la historia de este tipo de documentos fotográficos, identificando y localizando muestras de este patrimonio visual, así como ofrecer una primera cronología de los principales hechos que con dicho patrimonio se relacionan. Hasta este momento solamente se han podido localizar algunas imágenes que fueron publicadas en libros o revistas, pero no originales ni copias. Los resultados obtenidos parecen indicar que el fenómeno de la fotografía espiritista, a nivel español, tuvo un alcance y repercusión bastante reducido, si se compara con el panorama internacional.

\begin{abstract}
:
The so-called spiritualist photography was for a long time a sort of visual document practically forgotten by historians, critics and the general public. At the international level, since the end of the last century, different studies have claimed the interest of these images and the cultural context in which they appear. However, no equivalent studies have been carried out in Spain so far. In these circumstances, this article intends to make a first contribution to the history of this kind of photographic documents, by identifying and locating samples of this visual heritage, as well as by offering a first chronology of the main facts related to this heritage. Until now, only some images that were published in books or magazines have been found, but not originals or copies. From what has been seen so far, it seems that, in Spain, the phenomenon of the spiritualist photography had very limited scope and impact when compared to the international panorama.
\end{abstract}

Palabras clave: historia de la fotografía; espiritismo; fotografía en España; documentación; patrimonio visual

Keywords: History of photography; spiritualism; photography in Spain; documentation; visual heritage 


\section{Introducción}

Se conoce por fotografía espiritista ${ }^{1}$ a un tipo de fotografía en el cual además de la impresión de los personajes retratados se obtiene la de uno o más supuestos espíritus de fallecidos, a menudo con una textura translucida.

En el estudio de la fotografía espiritista no se puede descuidar que su origen lleva asociado una carga ideológica confrontada en dos posiciones, la de los creyentes y la de los escépticos. Seguramente por eso fue durante décadas un subgénero prácticamente olvidado por los historiadores e ignorado por la crítica y el público. Sin embargo, con una mayor conciencia del impacto social y cultural del espiritismo en su momento, y alejados de la confrontación dialéctica aludida, los historiadores de la fotografía, del cine y de la cultura visual han comenzado a tratar la fotografía espiritista como un factor importante en la experiencia de la Modernidad.

Desde finales del siglo pasado, un conjunto de exposiciones han reivindicado el interés de estas imágenes y el contexto cultural en el cual aparecen. En el año 1997 se exhibió en el Museum Abteiberg de Mönchengladbach Im Reich der Phantome: Photografie des Unsichtbaren, trasladándose en 1998 primero a la Kunsthalle Krems, en la Baja Austria; y luego en el Fotomuseum Winterthur de Zurich. En 1999 se exhibió en Berlín Trascendentale Fotografie. En el 2001 la exposición Faces of the living Dead. The Spirit Photographyof Mrs Ada Deane se expuso en el Contemporary Art Space de Camberra. Dos años después pudo verse Spiritus en el Riksutställningar de Estocolmo y The Disembodied Spirit en el Bowdoin College Museum of art de Brunswick. En el año 2004 se exhibió la muestra titulada Concerning the Spiritual in Photography en el Photographic Resource Center en la Boston University. A esta exposición siguió Le troisième oeil. La photographie et l'occulte, en su versión francesa, o The Perfect Medium: Photography and the Occult, en la americana. Comisariada conjuntamente por Clement Chéroux y Andreas Fischer en el 2004 para la Maison Européen de la Photographie de París y el 2005 para el Metropolitan Museum de Nueva York, se

\footnotetext{
1 También ha recibido otras denominaciones como fotografía espectral, trascendental, espontánea o psíquica.
} 
trata de la muestra más importante y con mayor publicidad de las que se han realizado. De nuevo en el Met, entre finales del 2012 y principios del 2013 pudo verse Faking It: Manipulated photography before Photoshop que con un sesgo que deja claro el título, una parte representativa de la selección eran fotografías espiritistas. Finalmente, en el 2015 la muestra Spirit Photography se expuso en el Aspen Art Museum de Colorado.

Por otro lado, la bibliografía ha ido creciendo. A los documentados catálogos Im Reich der Phantome (Fischer \& Loers 1997) y Le Troisième œil/The Perfect Medium (Apraxine et al, 2004/2005), le había precedido el trabajo de Tom Gunning (1995) que analizaba la fotografía espiritista en el contexto de la compleja relación de la imagen con aquello que parece documentar. Jolly (2006) ha explorado la fotografía de espíritus desde la década de 1870 hasta los años 30 del siglo XX y su impacto psicológico. Harvey (2007) ha analizado la fotografía de espíritus desde la perspectiva espiritual, científica y artística mientras que Kaplan (2008) ha abordado la temática centrándose en un estudio de caso. García Felguera (2008), por su parte, ha tratado con brevedad el caso de algunas fotógrafas espiritistas británicas en el contexto más general de fotógrafas y ciencia. Guixa (2009), en su tesis doctoral, aborda la fotografía espiritista en su estudio sobre la conquista de lo invisible al ojo humano a finales del siglo XIX mediante técnicas como los rayos X. Finalmente, Pablo Santoro (2014) se centra en el contexto británico posterior a la primera Guerra Mundial.

En conjunto, todos los trabajos citados se han ocupado del fenómeno de la fotografía espiritista esencialmente en el mundo anglosajón y francés. Fuera de estos entornos geográficos existen escasos trabajos académicos. Alessandra Violi (2004) realiza una aproximación hermenéutica a las fotografías fantasmales tomadas por el médico y criminólogo italiano Cesare Lombroso en el transcurso de sus investigaciones con médiums. También el Museo Roca - Instituto de Investigaciones Históricas de Buenos Aires se ha ocupado del tema. En noviembre de 2006 organizó la exposición Imágenes de lo Oculto. Por otra parte, dos de sus investigadores han abordado el estudio de este tipo de documentos visuales en el país sudamericano (Corbetta \& Savall 2013; 2017). 
En el caso de España, José Rafael Abascal (1990), en su historia del espiritismo en Andalucía en el siglo XIX, reproduce algunos textos de la prensa especializada relacionados con el tema. José Manuel Torres Martínez (1998) alude a ello en su tesis doctoral sobre la fotografía científica en Barcelona. Mucho más recientemente, Andrea Graus (2014), en su tesis doctoral sobre las investigaciones psíquicas en España entre 1888 y 1931, hace un breve inciso en la materia al tratar sobre la opinión de un investigador psíquico. Fuera de estos trabajos, el resto son breves menciones, referencias o notas en dispersos estudios sobre fotografía, literatura o antropología.

En tal contexto, este artículo pretende hacer una primera aportación a la historia en España de este tipo de documentos fotográficos. Más que realizar una reinterpretación contemporánea, lo que se pretende es identificar y localizar dicho patrimonio visual para hacerlo asequible a historiadores, antropólogos, fotógrafos y público en general. De forma paralela se desea ofrecer una primera cronología del contexto relacionado con dicho patrimonio. Este conocimiento a ha de permitir un primer bosquejo del nivel de contribución de la fotografía espiritista en las corrientes de Modernidad en España.

\section{Nota metodológica}

Tratándose de un trabajo que se puede considerar seminal, la investigación de campo ha consistido por una parte en la recuperación bibliográfica de artículos publicados en prensa espiritista o general en la época de estudio. Esta tarea resulta compleja debido a la dispersión de fuentes y porque una parte considerable de los ejemplares que deberían consultarse simplemente no están disponibles en bibliotecas públicas. Localizar y consultar ejemplares de particulares resulta, en el mejor de los casos, lento y complejo. Lo mismo ocurre con libros y folletos, alguno de los cuales a día de hoy todavía no hemos podido localizar.

Estas fuentes bibliográficas y hemerográficas primarias permiten construir un relato sobre la recepción de la fotografía espiritista como innovación foránea tanto como aproximarse a las particularidades del desarrollo de tal práctica en 
España. Estas mismas fuentes proporcionan también una parte del material visual generado. Otra fuente de imágenes deberían ser los archivos fotográficos y las colecciones privadas. En ese sentido las dificultades también son considerables y los resultados hasta ahora casi infructuosos.

El resto del trabajo consiste en un análisis de las fuentes y la construcción de un discurso inteligible.

\section{Inicios de la fotografía espiritista}

Hasta el siglo XVIII y a lo largo de centurias los adelantos tecnológicos habían sido exiguos si se compara con los que se producirían después. La revolución industrial implicó una enorme transformación económica, social y tecnológica. Durante la segunda mitad del siglo XIX se produjo una aceleración intensa de cambios y de innovaciones técnicas. Avances tales como el telégrafo, la radio, el teléfono o los rayos $\mathrm{X}$, permitieron la comunicación casi instantánea a gran distancia o ver realidades invisibles hasta ese momento. En términos generales, la proliferación de instrumentos y procedimientos científicos e industriales favorecía el optimismo sobre lo que era técnicamente posible. En este contexto, la fotografía parecía ofrecer a la vez un canal para satisfacer el deseo de comunicarse con los muertos que prometía el espiritismo y una prueba de tal "transcomunicación".

El origen del espiritismo moderno suele situarse en 1848, cuando dos jóvenes hermanas, Kate i Margaretta Fox, estando en su casa en Hydesville en el estado de Nueva York, escucharon unos crujidos y golpes de origen aparentemente desconocido, que se repetirán los días siguientes, siendo testigos los vecinos de lo que consideraron un diálogo inteligente. Con el tiempo las jóvenes hicieron representaciones públicas en las cuales presuntamente se comunicaban con los muertos, convirtiéndose así en médiums famosas. Muchos otros médiums, tanto profesionales como aficionados, empezaron a practicar también sesiones en las cuales se comunicaban con los fallecidos mediantes golpes secos; o bien caían en trance y, bajo el control de un espíritu guía intermediario, hablaban con las voces de otros espíritus que querían comunicarse con los vivos. Se establecieron 
protocolos y se construyeron discursos que servirían de dogma para las asociaciones y movimientos religiosos que proliferaron.

El invento de la fotografía espiritista suele atribuirse a un aficionado, William $\mathrm{H}$. Mumler de Boston. En octubre de 1861, realizando un autorretrato, capturó la imagen del presunto espíritu de un primo fallecido unos años antes. Un amigo espiritista inmediatamente reconoció el fenómeno como una prueba significativa de la comunicación con los espíritus, con lo que publicó la noticia en dos periódicos especializados. Los espiritistas comenzaron a visitar su estudio en tropel y su fama se expandió. Mumler terminó dejando su trabajo de joyero para dedicarse plenamente a este tipo de fotografía que contó con una gran demanda, espoleada por las pérdidas humanas de la Guerra Civil americana (1861-1865). En su estudio, las personas interesadas podían adquirir copias de fotografías de espíritus por el precio de un souvenir y las imágenes de espíritus se utilizaban en las carte-de-visite, pequeños retratos cuyo tamaño era el de tarjetas de visita, extremadamente populares en esa época (Gettings, 1978; Jolly, 2006). En 1869 fue acusado estafa, pero fue absuelto por falta de pruebas (Jolly, 2006; Kaplan, 2008).

Unos años después la obtención de fotografías espiritistas llegó a Gran Bretaña de la mano de Georgina Houghton, una inglesa de clase alta, nacida en las Islas Canarias, que como otras personas de su condición había experimentado con el nuevo pasatiempo de la fotografía y también con el espiritismo. Cuando supo sobre las actividades de Mumler, se interesó rápidamente por ellas. En 1872 conoció a Frederick Hudson, un fotógrafo profesional quien inmediatamente obtuvo resultados positivos. Pero con una celeridad semejante le llovieron las sospechas de fraude desde las propias filas espiritistas, siendo expulsado de ellas en 1874. (Jolly 2006; García Felguera 2008; Guix 2009).

En Francia, la fotografía espiritista aparece algo más tarde, debido a la posición cautelosa que mantuvo Allan Kardec -en realidad Hippolyte Léon Denizard Rivail, guía y codificador del espiritismo francés. Cuando las primeras noticias sobre las imágenes de Mumler llegaron a Francia, Kardec se mostró interesado, pero también receloso, citando, por ejemplo, un caso de de doble exposición 
accidental y el comercio de imágenes recreativas con doble exposición en Inglaterra (Kardec, 1863).

Sin embargo, tras la muerte de Allan Kardec en 1869 el movimiento espiritista francés pasaba por una etapa de debilidad. Su sucesor, Pierre-Gaëtan Leymarie, vio en la fotografía un instrumento para intentar persuadir a la opinión pública que el espiritismo era más una disciplina racionalista que una religión. Por ello, cuando en 1873 Edouard Buguet aparece en escena produciendo fotografías espiritistas en su estudio de París, Leymarie ve una magnífica oportunidad (Chéroux, 2005).

Buguet sostenía que su cámara y las placas fotográficas eran magnetizadas antes de una sesión y afirmaba que el espíritu le controlaba en estado de trance durante la exposición de la placa. Sus fotografías eran de mayor calidad que las anteriores y tuvo un éxito abrumador. Pero en junio de 1875 fue procesado por fraude. Inmediatamente confesó haber utilizado la doble exposición y maniquís o ayudantes convenientemente ataviados para emular a los espíritus. La policía encontró abundantes pruebas en su estudio. Pese a ello, y a que durante el juicio describió detalladamente el proceso fraudulento, los testigos le defendieron. Todos rechazaron que se tratara de un engaño y cuando fueron confrontados con el acusado y lo escucharon de su boca, abandonaron la tribuna protestando que se pretendiera que creyeran la declaración del acusado antes que lo que habían contemplado con sus propios ojos. Finalmente, Buguet fue condenado a un año de cárcel. Algunos espiritistas sostuvieron que el juicio y la confesión habían sido un montaje de la iglesia católica para desacreditar el espiritismo, lo que fue ampliamente aceptado dentro del movimiento. Pero el impacto de su confesión y condena desacreditó notablemente estas fotografías fuera del espiritismo (Chéroux, 2005; Jolly, 2006).

Buguet no fue el único en comercializar fotografías en París. Algunos espiritistas franceses interesados en la producción de Mumler compraron algunas de sus imágenes, pero como el costo unitario resultaba alto, encomendaron reproducciones a Claude Joseph Choisy, conocido profesionalmente por Saint Edme - uno de los fotógrafos y técnicos que había examinado el proceso de 
Buguet antes de que Leymarie se decidiera a bendecir su producción espiritista (Chéroux, 2005). En abril de 1875, cuando la policía registro su domicilio, encontró 40 fotografías espiritistas (Lestang, 2017). Alguna carte-de-visite de Saint Edme llegó a España. En concreto en el Museu Frederic Marès de Barcelona se conserva una de ellas (F1) procedente de álbumes familiares de la Ciudad Condal, sin que se conozcan más detalles.

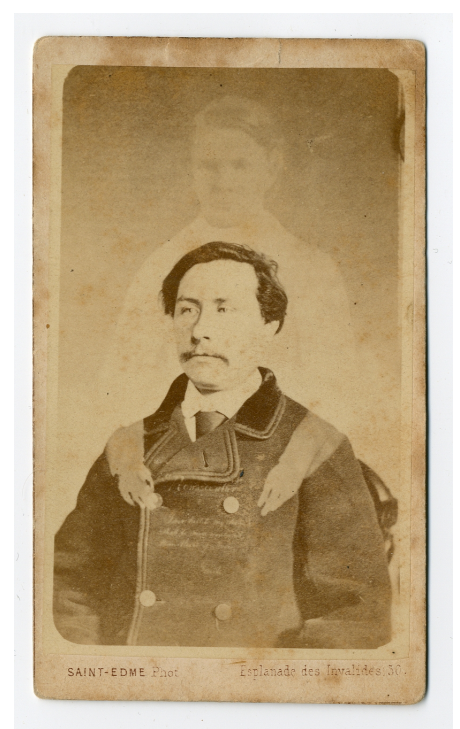

F1. Retrato de un hombre y un espíritu del fotógrafo Saint Edme. Fuente: Museu Frederic Marès. No de registro MFM-S-21984

Mumler, Buguet y Hudson centraban su actividad espiritista en los retratos realizados mediante luz natural. Pero William Crookes usó las entonces modernas lámparas eléctricas, lo que le permitió también hacer fotografías a plena luz en sus experiencias de investigación con la médium Florence Cook (Jolly, 2006).

Crookes era un eminente científico, uno de los más importantes del siglo XIX, y utilizó la fotografía en sus investigaciones para inmortalizar lo que consideraba evidencias de los fenómenos psíquicos de materialización que provocaban los médiums. Como Crookes tenía un alto crédito científico, muchos otros investigadores siguieron su ejemplo, convirtiéndose esta práctica experimental en el origen de buena parte de fotografías de espíritus que han llegado hasta nuestros días gracias a su publicación en libros y revistas. 


\section{La primera fotografía espiritista en España}

Desde finales de la década de 1860 la prensa espiritista española había publicado noticias sobre fotografía procedentes sobre todo de la Revue Spirite, incluida una traducción ya póstuma del cauteloso artículo de Kardec que apareció en noviembre de 1869.

El número del 5 de febrero de 1872 de La Revelación: Revista espiritista alicantina reproducía un texto titulado "Fotografía espiritista" que se había publicado el año anterior en El Criterio espiritista $(K, 1872)$. En la reunión de la entonces incipiente Sociedad Alicantina de Estudios Psicológicos concibieron la idea de hacer un ensayo similar, como el propio artículo sugería. Por ello celebraron una sesión el viernes 5 de enero para obtener de los espíritus las instrucciones precisas. Con los detalles en la mano, acudieron al retratista Jules Planchard Theville, dueño de uno de los gabinetes de fotografía que había en la ciudad (Rodríguez Molina \& Sanchís Alfonso, 2013; Linares Albert \& Poveda Bernabé, 2014) y donde el experimento espiritista se llevó a cabo. Por lo que parece, el fotógrafo no puso reparo alguno en realizar la prueba.

El médium Juan Pérez realizó una evocación en la misma galería y “se le presentó el espíritu de su padre, que, enterado del caso, deseaba salir retratado junto con su hijo" (Fotografía espiritista en Alicante, 1872a)². Planchard realizó la fotografía al médium y luego se dirigió a la cámara oscura. Al rato, salió diciendo que "notaba dos manchas en el cliché con formas humanas, una a la derecha y otra a la izquierda del médium que se había retratado”. Para el autor del artículo

habían salido en el cliché los retratos de dos espíritus. El que estaba a la derecha era el padre del mencionado J. Pérez [...], y se hallaba reclinado sobre su hombro; y el de la izquierda fija la vista en el suelo en actitud grave y respetuosa.

Se trata de la primera fotografía espiritista en España de la que tenemos noticia. No parece que el retrato se llegara a publicar, pero, según el Criterio espiritista,

\footnotetext{
2 El autor del artículo es probablemente Ausó Monzó. A menudo, como ocurre en este caso, las contribuciones no tenían firma. El texto fue reproducido en la Revista espiritista: periódico de estudios psicológicos, (febrero de 1872, $\mathrm{n}^{0}$ 2, p. 44-45) y en El Criterio espiritista, (marzo de $\left.1872, \mathrm{n}^{\circ} 3 \mathrm{p} .42-43\right)$.
} 
se realizaron muchas reproducciones, aunque desconocemos si ha sobrevivido alguna.

Parece razonable el interés de un fotógrafo profesional por conocer de cerca los detalles sobre este tipo de fotografía. Unos años antes, no pocos fotógrafos habían sentido curiosidad o interés por el magnetismo, que se había puesto de moda (Fontanella, 1980).

La noticia de la obtención de la fotografía de espíritus debió estar en el boca a boca de la población alicantina. Dos semanas después, el 20 de enero, aparecía en El Semanario Católico local una crítica satírica sobre los hechos. La réplica de La Revelación apareció en el mismo número citado del 5 de febrero. Sería el inicio de una áspera polémica entre los dos medios de comunicación (Ramos 2004).

Los ensayos fotográficos en Alicante continuaron. En agosto El Criterio espiritista de Madrid menciona que

la misma Sociedad Alicantina de Señoras, por el celo de su digna presidenta, consiguió, colocada ésta en el foco del aparato fotográfico, y de noche, una figura que ninguna semejanza tenía en nada con ella, representando á una reina con manto y corona, de facciones y aspecto bellísimos; siendo de lamentar que por distracción del fotógrafo, hija de la sorpresa, desapareciese en su mayor parte tal figura, al herir en ésta la luz del día por no haber fijado la imagen seguidamente (Fotografía espiritista, 1872).

El éxito en Alicante naturalmente interesó a otros cenáculos como la Sociedad espiritista española de Madrid, aunque con pocos o nulos resultados (Fotografía espiritista en Alicante, 1872a; Fotografía espiritista en Alicante, 1872b). Lo mismo parece que ocurrió con la Sociedad Barcelonesa Propagadora del Espiritismo (Fotografía espiritista en Alicante, 1872c).

\section{Buguet, visto desde España}

En febrero de 1874, la Revue Spirite comunicaba que, después de un minucioso escrutinio daba finalmente total credibilidad a Buguet y sus fotografías de 
espíritus (Leymarie, 1874a). Pocos días después la noticia aparecía ya traducida en el periódico sevillano El Espiritismo (Leymarie, 1874b). En España no todos los espiritistas estaban dispuestos a aceptar incondicionalmente las noticias que llegaban desde París. Tanto en El Espiritismo, como en El Criterio espiritista de Madrid se publicaron algunos artículos que planteaban dudas, lo que sería contestado ácidamente desde la Revue Spirite (Rousset-Guillot, 1874).

José Rafael Abascal nos advierte de la existencia de "una nutrida correspondencia entre los dirigentes espiritistas sevillanos con otros de fuera de la ciudad" (Abascal, 1990, p. 227). El director de El Espiritismo, Francisco Martí Bonneval, remitió una carta a Manuel González Soriano, un amigo espiritista afincado entonces en Ciudad Real, adjuntando cuatro tarjetas fotográficas obtenidas en París, solicitadas desde la capital hispalense. Reconoce la nulidad de los resultados al igual que anteriormente con las fotografías espiritistas que habían intentado en Sevilla. En estas condiciones Francisco Martí no podía aceptar la veracidad del fenómeno.

El método seguido consistía en intentar sincronizar las peticiones de manifestación realizadas en las sesiones de Sevilla con las imágenes obtenidas por Buguet en París. Pero las fotografías francesas recibidas no cumplían las expectativas.

En la respuesta de Manuel González Soriano - fechada el 26 de abril, pasa revista sistemática a las numerosas formas de engaño que conjetura, juzgando que

con tanto medio de mistificación, con tanto elemento para la superchería, no es en verdad prudente ni sensato aceptar como legítimo un fenómeno de esta naturaleza, máxime cuando todavía no existe una razón clara y lógica que explique y justifique la forma y condiciones en que se le supone se produce. En efecto, todo objeto que impresione al ojo de la cámara oscura (objetivo), impresiona también al ojo humano, (retina) (Abascal, 1990, p. 233).

Consecuente con su pensamiento, sostiene que el fotógrafo no necesita ser médium, ya que solamente registra lo que cualquiera debe poder ver ${ }^{3}$. Y termina

\footnotetext{
3 No todos los espiritistas estaban de acuerdo con esa idea. Basándose en el éxito del uso de la fotografía para poder leer partes ilegibles por el deterioro de manuscritos, se infería que el objetivo podía captar otros aspectos reales no observables a simple vista (Mateos, 1873).
} 
con una recomendación: "la primera circunstancia que debe prevenir en contra, respecto a la fotografía de los espíritus, es la de que el médium sea fotógrafo, que viva del arte, y exija ganancia alguna por esta clase de trabajo" (Abascal, 1990, p. 236).

En medio de un intenso debate sobre las fotografías de Buguet, las cartas comentadas ofrecían una detallada perspectiva crítica desde dentro de la ortodoxia espiritista. Por ello, Francisco Martí consideró publicarlas en El Espiritismo en la edición del 15 de julio.

El mismo julio de 1874, el semanario de actualidad Revista Europea de Madrid insertaba la noticia de la popularidad que estaba alcanzando la fotografía espiritista (Boletín de Ciencias y Artes, 1874). El impacto de la actividad de Buguet - que no se cita explícitamente en el artículo- sobrepasaba ya el mero entorno espiritista, por lo que resultaba oportuno informar sobre ello. La nota es totalmente escéptica y no duda en calificar de "inocentes" a quienes creen reconocer a los allegados junto a sus retratos. Se atribuye las falsificaciones a meras dobles exposiciones.

En octubre, José María Fernández Colavida (1874), director de La Revista espiritista: Periódico de estudios psicológicos de Barcelona publica una extensa reflexión sobre la fotografía espiritista. Por una parte, critica las voces escépticas expresadas en El Espiritismo y El Criterio espiritista. Luego reconoce

que algunas ó la mayor parte de las fotografías recibidas en España, ofrecen muchas dudas, tanto por la falta absoluta del parecido con los Espíritus evocados, como por la forma rutinaria de un ropaje, casi siempre el mismo, poco conforme con la infinita variedad de creaciones fluídicas que los Espíritus pueden presentar á foco del objetivo.

Fernández Colavida añade que está acumulando una colección de fotografías espiritistas que considera falsificaciones para, finalmente, confesarse optimista sobre el futuro de la fotografía espiritista.

El tema era candente por ello se recababa la opinión de fotógrafos profesionales, como es el caso de Pere Fàbregas, que narra los detalles de una sesión en su taller con unos amigos que le han consultado, dos médiums, su dependiente. La 
primera imagen que obtiene no da resultado alguno, según la afirmación de los propios médiums. Ahora bien, en el segundo caso, las cosas cambian:

Ensayamos un segundo, y con notable extrañeza por mi parte, vimos aparecer en él una imagen positiva de un sujeto desconocido. Este hecho, verdaderamente raro, nos hizo vacilar en nuestras opiniones y casi declarar victoriosos á los médiums, que nos consideraban derrotados. Antes de cederles por completo el triunfo, y creyendo todavía que el fenómeno ocurrido podía tener natural explicación en algún hecho que pudo haber pasado desapercibido para nosotros, resolvimos sacarlas positivas del cliché, que nos dieron pruebas negativas sobre el papel, de donde pude deducir inmediatamente que en aquel fenómeno nada habían podido influir los espíritus, ni á ellos en modo alguno debía atribuirse, puesto que estudiando la obtención del cliché, podía darse al fenómeno explicación clara ó incontestable (Fabregas, 1874).

Y después de dar unas largas explicaciones técnicas sobre el proceso fotográfico seguido termina diciendo que

inadvertidamente quedó el cristal apoyado sobre un cliché que había ya servido, y que allí se encontraba con el objeto de ser borrado, porque no pensábamos volverle á utilizar. Sucedió incidentalmente que el cliché citado se hallase entre la luz y el cristal preparado, por lo que indudablemente fué impresionado en las partes en que la luz hirió de un modo directo. Sirviéndonos después del revelador, hicimos aparecer la imagen en todos sus detalles. La imagen obtenida era una, positiva de la negativa en que habíamos apoyado inadvertidamente el cristal preparado, y que fué luego la causa del fenómeno en cuestión.

La fama que Buguet tenía entre los espiritistas franceses fue en aumento a partir de junio de 1874 cuando la Revue Spirite comenzó a publicar fotografías acompañadas de testimonios que afirmaban reconocer a los espíritus que en ellas aparecían. En la época, la dificultad técnica y el coste económico de estas reproducciones en una revista de 1.500 ejemplares, demuestra su implicación en dar credibilidad a Buguet y al fenómeno (Chéroux, 2005). Ahora bien, el asunto llamó la atención de la policía que no vio en ello más que una estafa de manera que en abril de 1875 Buguet fue arrestado. 
En el mes de junio se inició el juicio que se reflejó en la prensa espiritista española de forma desigual. Por ejemplo, La Revista espiritista no hizo mención alguna al proceso durante todo el año 1875. Por su parte, El Espiritismo se vio obligado a esperar al 15 noviembre para informar ya que no pudo editarse desde mediados de julio por orden del Negociado de Prensa del Gobierno Civil de Sevilla. Este tipo de suspensiones forzosas no eran nada extrañas y no estaban necesariamente vinculadas a la temática (García Rodríguez, 2003). Como contrapartida, en cuanto aparece de nuevo, le dedica un amplio espacio. En un primer artículo titulado "Proceso de Buguet y Leymarie" Francisco Martí revisa la postura escéptica de la revista plasmada en la correspondencia que durante al año anterior se había publicado; no olvida los insultos recibidos desde París; y, finalmente, celebra que la acción de la justicia haya puesto las cosas en su lugar (Martí Bonneval, 1875). A continuación, el periódico espiritista comienza a versar en español una extensa nota del Journal des débats politiques et littéraires (Bulletin judiciaire, 1875) en el que se detalla la crónica judicial. El contenido completo de la narración se alargaría durante meses.

\section{Fotografías espiritistas en Crevillent}

Hay que esperar veinte años para tener de nuevo noticias de fotografías espiritistas realizadas en España. Leemos en la Historia de la filosofía en España hasta el siglo XX que a principios de la década de los 90 “José Muñoz López, de Yecla, publicó varios artículos sobre los éxitos de la fotografía espiritista obtenidos en Crevillente con la médium doña Dolores Más” (Méndez Bejarano, 1928, p. 528). Por otra parte, Virginia Milner Garlitz (2007, p. 27) apunta que "había mucho escrito sobre la fotografía espiritista en el período, por ejemplo, los artículos de [Paul] Gibier o los de José Muñoz López de Yecla en 1891 mencionados por Méndez Bejarano”.

En 1892 -o quizás en 1893- se editó en Yecla lo que parece ser un opúsculo en defensa de la mencionada médium titulado Observaciones y crítica á un comunicado, contestando á injustas apreciaciones sobre el Espiritismo y la medium Dolores Mas (Ojeada retrospectiva, 1894). Por otra parte, La Soflama, 
y otros semanarios yeclanos hicieron diversas menciones de corte escéptico a esta médium durante el verano de 1892 (López Serrano, 1991).

También era crítico con dichas imágenes Manuel Otero Acevedo, un médico de origen argentino afincado en Galicia, precursor de los estudios de neurología en España y estudioso de la investigación psíquica experimental (Graus Ferrer 2014). Manuel Otero confiaba en la autenticidad de las fotografías espiritistas obtenidas por investigadores como Crookes, pero no creía que se trataran materializaciones de espíritus, sino exteriorizaciones de los médiums, el llamado "fantasma de los vivos" según la terminología acuñada por Gurney, Myers y Podmore (1886). Paralelamente consideraba fraudulentas las fotografías espiritistas obtenidas sin control científico y a menudo comercializadas.

En las fotografías de Crevillent, Manuel Otero critica de forma velada la credulidad de los espiritistas que defendían su autenticidad (Monge López, 2015). En un artículo publicado en La Ilustración artística se refiere a unas imágenes que, sin identificar su origen, por la fecha parece corresponderse con las de la población alicantina del Vinalopó:

las fotografías que vi en la reunión aludida ofrecen de notable sobre cuantas hasta ahora conozco las particularidades de haber sido conseguidas á la luz del día, estando la médium en perfecto estado normal y prestándose complacientes buen número de espiritistas á ser retratados con ella, sin exigencias de ninguna clase por parte de los mismos (Otero Acevedo, 1892).

Añade también que consciente de que no puede probar la falsedad de las imágenes, quiere

mostrar de qué manera pueden hacerse muy semejantes á las espiritistas, sin que intervengan en su obtención fuerzas desconocidas; basta un fotógrafo artista, que en el caso presente lo ha sido el Sr. Laurent4, al cual envío el testimonio de mi gratitud.

En su emulación Otero opta por una imagen en la que aparece posando él mismo a la vez que lo hace como falso espíritu, para que no pudiese objetarse de la realidad del montaje. Aclara que el procedimiento seguido es el mismo que el de

4 Debe referirse al “Sucesor de Lauren” (Rodríguez Molina \& Sanchís Alfonso, 2013). 
Buguet, doble exposición, aunque aclara que podría haber impresionado sucesivamente el positivo a partir de dos negativos distintos.

Así que, a finales de siglo XIX la fotografía espiritista en España, era un tema suficientemente popular para dar su salto a la literatura. En 1899 Pio Baroja escribe Medium, narración en la cual el personaje principal realiza una fotografía a la familia de un amigo y, al revelarla, observa una mancha obscura sobre la hermana de su amigo, una mujer con capacidades telequinésicas. La sombra es un espíritu que le está hablando al oído. Muy poco tiempo después, Valle Inclán, en el capítulo 5 de su novela por entregas La Cara de Dios, menciona en una fotografía la aparición de un espíritu responsable de los desmanes sobrenaturales que se producían en cierta vivienda.

\section{Publicación de fotografías}

Hacia finales de 1903 la lmprenta y Librería de Carbonell y Esteva5 de Barcelona publicaba un álbum con 38 fotografías espiritistas. Las 9 primeras fueron tomadas mayoritariamente en Manila en fecha desconocida, esencialmente con el médium de José Azas (F2), y pertenecían a la colección de un amigo suyo, el díscolo sacerdote catalán Salvador Pons i Torres, residente en Filipinas desde 1884 (Cruz, 2017), entonces un territorio español de ultramar. El resto de imágenes corresponden al médium de origen alemán establecido en Washington Theodor Hansmann.

En 1905 aparece en el semanario espiritista barcelonés Los albores de la verdad un artículo titulado "Una fotografía espirita” firmado por Daniel Grang, pseudónimo de Ángel Grinda Güinter (D. Ángel Grinda, 1908). El escrito nos hace saber que en los últimos días de diciembre había llegado a la población onubense de Isla Cristina el fotógrafo Carlos Colón. En esa época todavía era corriente esta actividad ambulante. Tras su llegada, los espíritus guías del grupo isleño Amalia Domínguez al que pertenecía Grinda les sugirieron que intentaran

\footnotetext{
5 Esta editorial publicaba abundante material de corte espiritista. El material gráfico fue seleccionado por Jacinto Esteva Marata con la pretensión de ofrecer una muestra de este tipo de imágenes (Esteva Marata, 1906a). Al menos existían 4 imágenes más que no fueron incluidas.
} 
realizar una fotografía espiritista. El retratista aceptó con facilidad la propuesta “á pesar de ser completamente profano en nuestras ideas”, según se nos específica. Adquirieron directamente las placas en un comercio y, después de unos ensayos guiados por los espíritus, alcanzaron el éxito:

La estupefacción del artista llegó al colmo al revelar la placa fotográfica que momentos antes le habíamos entregado y cuya revelación tuvo lugar á presencia de todos los asistentes al acto, viéndose, con general asombro, las tres figuras que aparecen en él además de las tres personas realmente colocadas delante del objetivo, causando emoción profunda el momento en que se produjo el trance total del médium, como puede apreciarse en la fotografía (Grang, 1905).

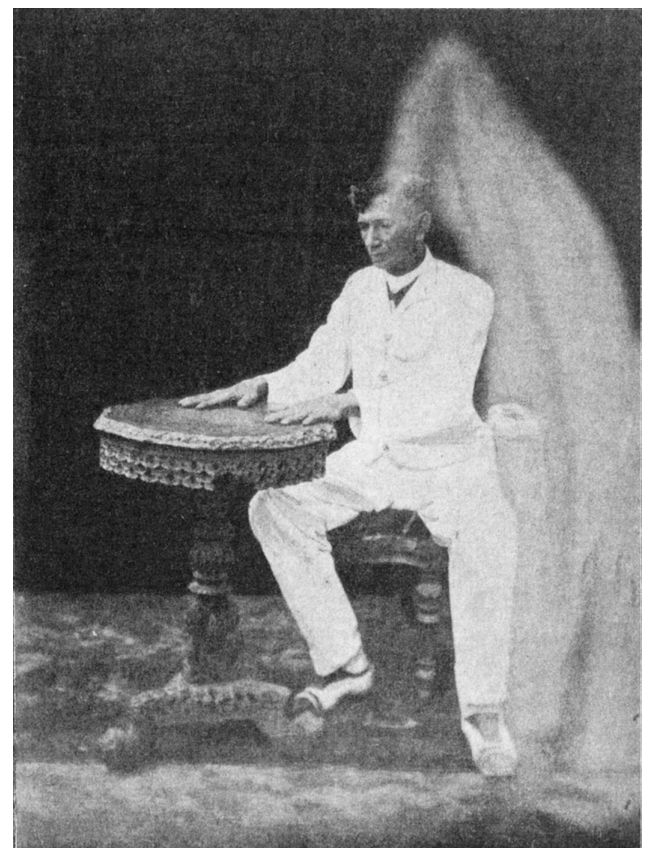

F2. Imagen de Azas concentrado sobre una mesa veladora con un fluido fantasmal emanando desde la cabeza.

Grinda pasa a describir los aspectos más relevantes relacionados con la toma de la imagen (F3) e indica que la parte inferior aparece velada, afectando al suelo y parte de las piernas de los retratados. Eso no tiene explicación lógica para el autor, pero añade que el fotógrafo, debido a la confusión por el sorprendente resultado y por su modestia declaro que "Tal vez se me velaría al desmontar el chasis”, lo que resultaba imposible para Grinda. 


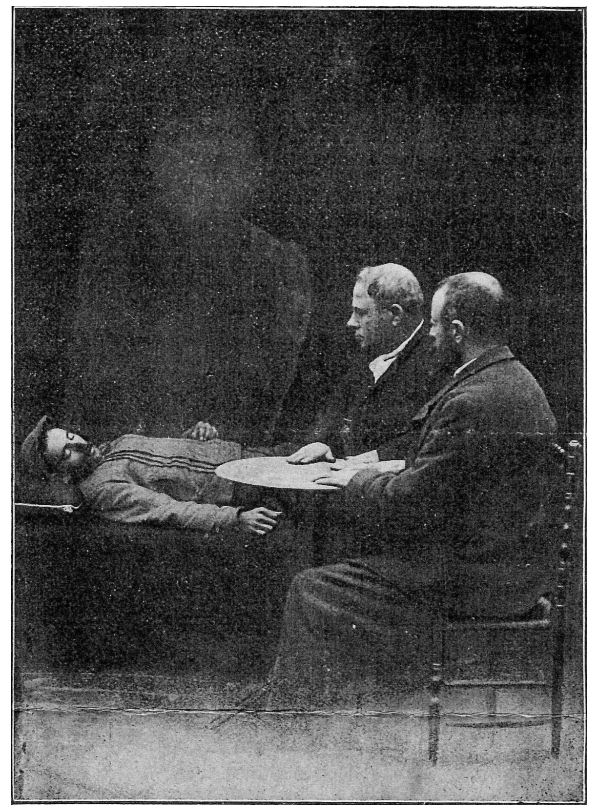

F3. Fotografía espiritista obtenida en Isla Cristina en diciembre de 1904. Grinda aparece a la izquierda, en primer término. Fuente: Los albores de la verdad.

En junio de 1906 Jacinto Esteva Marata, director de la revista Luz y Unión de Barcelona publica una carta remitida por Hansmann con detalles sobre sus progresos en materia de fotografía espiritista. Reproduce algunas de las imágenes que el corresponsal le había enviado, labor que continuará realizando en los números siguientes. Tales fotografías tienen un efecto catalizador casi instantáneo puesto que en el siguiente número Esteva Marata informa de fotografías obtenidas en Barcelona por el Grupo Amor y Vida

siguiendo las instrucciones dadas por el doctor Hansmann, que nos hacen augurar un feliz éxito; esperamos tan sólo para dar más detalles la obtención de una muy notable, prometida por el Guía del Grupo (Esteva Marata, 1906b).

Sin embargo, no hemos podido encontrar nueva información en los números de esta revista a los que hemos tenido acceso.

Por otra parte, autores como Josep Comas Solà (1907; 1908) o Alfredo Rodríguez de Aldao, bajo el pseudónimo de Aymerich (1911), presentaban también en esa época falsas fotografías de fantasmas basadas en la doble exposición. Por entonces no son extrañas las postales comerciales con tales efectos con finalidades recreativas, aunque aquí en lugar de figuras espectrales suelen 
aparecer modelos agraciados según el gusto del momento. Este tipo de productos fueron relativamente habituales hasta la guerra del 36 , aunque parece ser que en los años 40 todavía se observa la circulación de muestras ${ }^{6}$.

Las aludidas recreaciones no extinguían el interés por la fotografía de espíritus. En 1908, o poco antes, la editorial de temas místicos Biblioteca La Irradiación de Madrid, publicaba un folleto cuyo título es totalmente explícito: Instrucción práctica para el empleo de la fotografía al magnesio en las experiencias psíquicas y en la obtención de retratos de fantasmas y seres de ultratumba (Bibliografía, 1908). Se trataba de la traducción de un artículo de Emile Anastay (1906) publicado en Marsella.

El interés de las asociaciones espiritistas en este tipo de fotografía debía ser significativo, aunque no resultara siempre fácil el ensayo o la adquisición de positivos. En el Centro Espirita Esperanza Cristiana de Barcelona7 disponían de un pequeño archivo de fotografías de espíritus. Es interesante resaltar que su contenido consistía en algunas imágenes de origen todavía no determinado; el Álbum de fotografías espiritas (1903) que ya hemos comentado; y láminas extraídas del libro de Elisabeth Espérance, Al país de las sombras, publicado en el año 1900 también por Carbonell y Esteva. La cercanía en las fechas de publicación de las dos obras sugiere una de aproximada para la constitución de este pequeño archivo, así como la intención del responsable, al haber separado las imágenes del libro, que quedó por ello mutilado.

También las revistas de fotografía ofrecían noticias sobre el tema. En 1910, La Fotografía práctica se hacía eco del resultado final de una comisión creada por el diario londinense Daily Mail para investigar la realidad de la fotografía de espíritus y en la que los fotógrafos consideraron que ninguna de las imágenes presentadas había sido tomada en condiciones que impidieran el fraude (Torrés Martínez, 1998).

\footnotetext{
${ }^{6}$ La red recoge algún ejemplo: https://www.todocoleccion.net/postales-especiales/postalaparicion-espiritu-madrid-anos-1940-espiritismo-espiritus $\sim$ x42654338. [Fecha de consulta: 30 diciembre 2017].

7 Comunicación personal de Ramon Puig, cuya familia estuvo vinculada al Centro hasta su desaparición al final de la guerra civil y que heredó gran parte del archivo y biblioteca de la organización.
} 


\section{Fotografías del círculo María de Cartagena}

Hasta el momento, el testimonio más voluminoso que tenemos de fotografías espiritistas en España corresponde a las instantáneas obtenidas por el denominado Grupo María Cartagena durante el año 1913. Esto es debido a la publicación del diario de las sesiones espiritistas titulado Páginas íntimas de ultratumba en el cual reprodujeron diversas de las fotografías que habían obtenido en sus experiencias. La médium, "Luisa", probablemente fuera la esposa del autor del, Fulgencio Gómez Ros, militar y fotógrafo residente en Cartagena.

Según podemos leer, se obtuvieron diecinueve imágenes, de las cuales publicaron catorce. En un artículo firmado por el artista malagueño José Blanco Coris (1916), se reproducen tres de las fotografías realizadas por el grupo (F4, F5 y F6). Las mismas tres imágenes son las que publicaría en 1919 Julio Camino Galicia, médico y amigo de Blanco Corís, que es quien se las proporciona, en un capítulo de su libro Hipnotismo e Hipnoterapia.

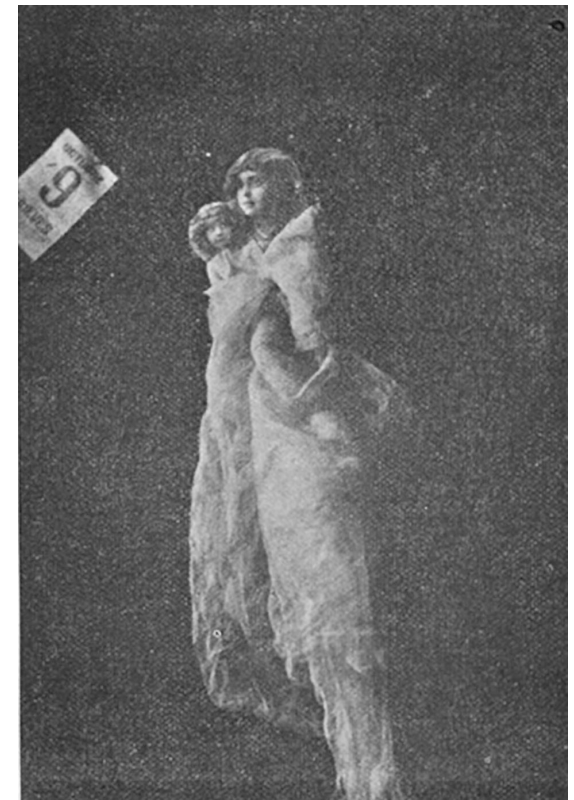

F4. Fotografía del espíritu guía María Ducondrait y de una niña identificada de Cartagena, (8 de octubre de 1913). Fuente: Páginas íntimas de ultratumba, p. 74 bis.

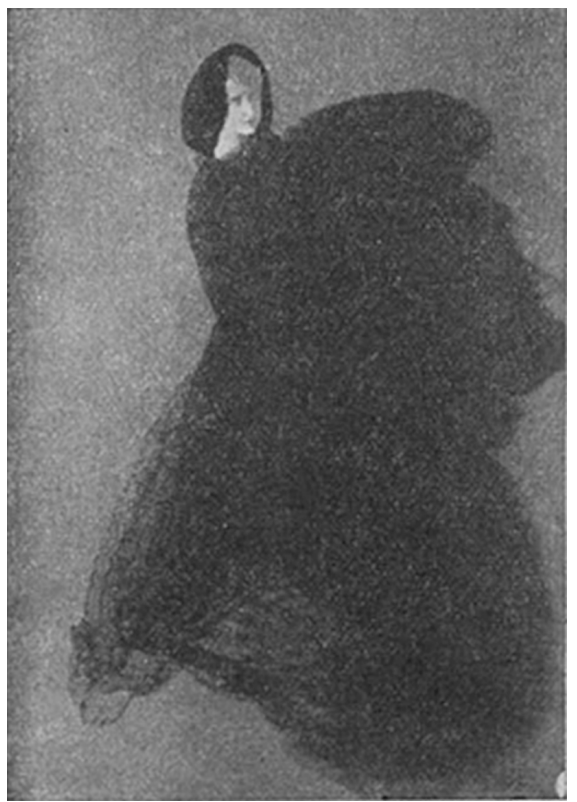

F5. Fotografía de Lolita la Castañera (22 de octubre de 1913). Fuente: Páginas íntimas de ultratumba, p. 80 bis. 


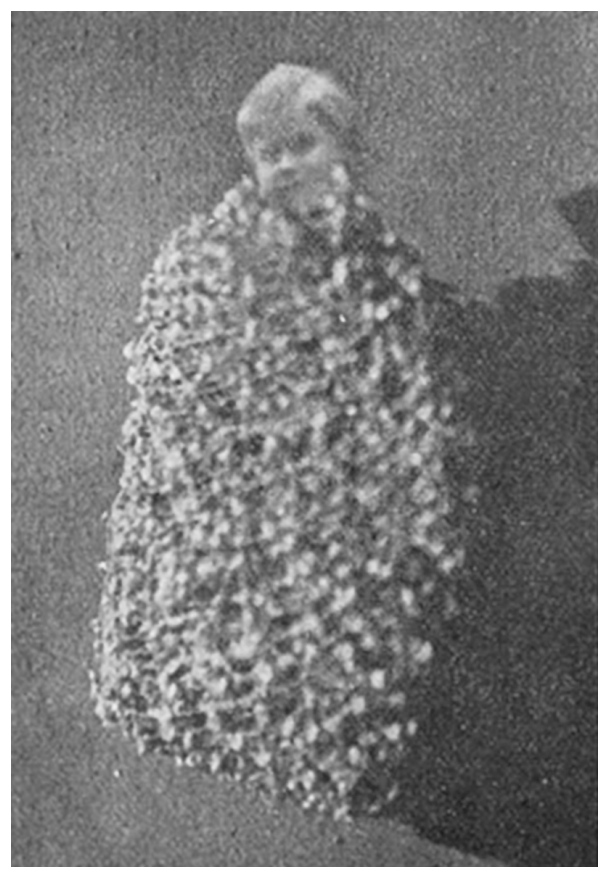

F6. Fotografía de niño no identificado (22 de octubre de 1913). Fuente: Páginas íntimas de ultratumba, p. 80 bis.

Camino facilita algunos de los datos que Blanco había ya publicado. Por otra parte, asegura conocer buena parte de la bibliografía espiritista y añade que esas fotografías constituyen testimonios materiales de la aparición de espíritus valorando su procedencia española "pues hasta la fecha sólo se habían obtenido fotografías de esta clase en el extranjero" (Camino Galicia, 1919, p. 87).

\section{Resurgimiento en Europa de la fotografía espiritista}

El volumen de pérdidas humanas durante la Primera Guerra Mundial trajo consigo, entre otras prácticas de duelo y de memoria, un resurgimiento popular del espiritismo, especialmente en el Reino Unido, pero también en otros países de Europa. La fotografía de espíritus no quedo exenta de esa reaparición en el devenir cotidiano.

Seguramente el caso más famoso de fotógrafo espiritista de la época fue el de Ada Emma Deane (1864-1957), que llegó a realizar más de 2.000 fotografías de espíritus por este procedimiento. El punto álgido de su popularidad devino como resultado de una imagen tomada el 11 de noviembre de 1922, durante los dos 
minutos de silencio mantenidos en la tercera celebración del Día del Armisticio. Por encima de la multitud se vislumbraban unos rostros borrosos en los que diversos testimonios de personas -el escritor Arthur Conan Doyle entre elloscreyeron reconocer a sus muertos. Doyle expuso reiteradamente la fotografía en la que vislumbraba a uno de sus sobrinos, llevándola consigo en su segundo viaje de promoción del espiritismo por EUA y Australia, donde el escritor reunió grandes multitudes que se conmovían especialmente ante esta imagen (Jolly, 2006; Fischer, 2005; Winter, 1996; Santoro Domingo, 2014).

En España, la prensa generalista se hizo eco esporádicamente de las fotografías que exhibía Doyle, debido a su fama como escritor. Por ejemplo, el Mundo Gráfico reproducía una fotografía del espíritu de su hijo fallecido, aunque el texto dice erróneamente hija (España, 1920). Tras el fallecimiento del autor británico, el Heraldo de Madrid incluyó también una imagen (Hahin, 1930). Durante los años siguientes hasta la guerra hay algunas menciones en artículos escépticos como el de Ilse W. de Rivera (1936) "El espiritismo y sus trucos". En estas publicaciones aparecen fotografías de aportes y ectoplasmas de los médiums, pero trátese siempre de material foráneo.

\section{Conclusiones}

La llegada conjunta del espiritismo moderno y de la fotografía puso la nueva tecnología a disposición de la creencia en los espíritus, estableciendo una alianza entre aparatos y apariciones, en un intento de reconciliación entre razón y fe que, de tener éxito, debía terminar confirmando las ideas espirituales. Al fin y al cabo, también se confiaba en la capacidad infalible de la cámara para capturar la realidad, de aquí su uso como un instrumento para la investigación científica.

El espiritismo eran entonces un movimiento de vanguardia que consideraba que sus descubrimientos y revelaciones formaban parte del progreso al igual que la ciencia i la tecnología. Precisamente por ello y por la dimensión social que alcanzó, hoy reconocemos la necesidad de tratarlo como un elemento significativo de la experiencia de la Modernidad. Sin embargo, el impacto de la fotografía espiritista en España no parece haber sido comparable al de Francia, 
Reino Unido, o EUA. Podemos buscar razones en el propio desarrollo de la historia de la fotografía en España, que sufrió cierto retraso si lo comparamos con el país vecino, cuna de la técnica. En la ausencia de científicos e investigadores que trabajaran en condiciones de laboratorio con médiums y que, por lo tanto, estuvieran en condiciones de capturar imágenes de espíritus. En las endémicas restricciones a las libertades que tampoco debieron favorecer este tipo de prácticas. Todos estos motivos convergen hacia la idea de que la relativamente escasa incidencia de la fotografía espiritista no sería sino una muestra más de las dificultades de España para adaptarse a las nuevas tendencias de la Modernidad filosófica i científica que florecían en los estados donde había triunfado el protestantismo o la revolución burguesa.

Pese a lo dicho, este tipo de documento gráfico existió. Si juzgamos por lo que hasta ahora sabemos, incluyendo las de Manila, la cantidad de imágenes identificadas puede situarse en 40 o 50, cifras muy alejadas de los centenares o miles de los países de referencia. Téngase en cuenta que las imágenes que aparecen en los libros y en la prensa generalista editados en España, hasta donde conocemos, siempre proceden del extranjero, a excepción de las que publica Julio Camino Galicia en 1919, quien supone erróneamente que no se habían obtenido fotografías de tal índole con anterioridad en territorio español. Dado el interés de este autor por la temática, refuerza la idea del escaso impacto de tal actividad fotográfica, incluso entre los círculos de especialistas. Eso no significa que el asunto no interesara, pero parece que sobre todo se planteó en un terreno más teórico que práctico, salvo en algunas experiencias en cenáculos espiritistas locales. El debate alcanzó su cénit durante el proceso de auge y caída de Buguet hacia 1874, tardando todavía unos años en llegar a la literatura.

Por el momento se han podido identificar y localizar algunas fuentes bibliográficas y hemerográficas que contienen muestras de este tipo de patrimonio visual. También se han encontrado referencias a otras imágenes de las que circularon copias, pero no se ha localizado ninguna. Al tiempo transcurrido hay que sumar los estragos de la Guerra Civil y la postguerra que redujo el espiritismo a una existencia clandestina. 
La historia completa de la fotografía espiritista en España está por escribir. Será necesario acceder a nuevas fuentes primarias para poder completar lo que aquí se ha esbozado. Sin embargo, de lo visto hasta ahora parece que el fenómeno tuvo menor importancia para el conjunto de la historia de la fotografía española y de la historia de la cultura de forma más general, si se compara con el panorama internacional.

\section{Agradecimientos}

Es imposible citar aquí a todas las personas y entidades con las que estamos en deuda. Sin embargo, no podemos dejar de mencionar a Laia Foix, del Institut d'Estudis Fotogràfics de Catalunya; David Santamaria, del Centre Barcelonès de Cultura Esperita; Ramón Puig, albacea extraoficial de la documentación del Centro Espirita Esperanza Cristiana de Barcelona; y, finalmente, al Instituto Homeopático y Hospital de San José de Madrid.

\section{Referencias bibliográficas}

Abascal y Sáinz de la Maza, J. R. (1990). Espiritistas andaluces en el siglo XIX. Alcalá de Guadaira: Muñoz Moya y Montravieta editores.

Álbum de fotografías espiritas (1903). Barcelona: Casa Editorial de Carbonell y Esteva.

Al Semanario Católico (1872). La Revelación: revista espiritista alicantina, (3), 35-36.

Anastay, E. (1906). Instruction pratique pour l'Emploi de la photographie au magnésium dans les expériences psychiques. Bulletin du Centre d'études psychiques de Marseille, (20), 117-127.

Bibliografía. (1908). Luz y Unión, (10), 320.

Apraxine, P., Canguilhem, D., Chéroux, C., Fischer, A., Schmidt, S. (2004/2005) Le Troisième oil: La photographie et l'occulte. Paris: Gallimard / The Perfect Medium: Photography and the Occult. New Haven: Yale University Press.

Aymerich (1911). El Hipnotismo prodigioso. Madrid: Librería de Pueyo, 2 vol.

Blanco Coris, J (1916). Casos fehacientes de la mediumnidad. España Médica, (184), 7-10.

Boletín de Ciencias y Artes (1874). Revista Europea, (21), 95-96. 
Bulletin judiciaire (1875). Journal des débats politiques et littéraires, 2-3.

Camino Galicia; J. (1919). Hipnotismo e Hipnoterapia. (Sus aplicaciones a la medicina). Teoría, fenomenología clínica y técnica. Madrid: Gráfica Excelsior.

Chéroux, C. (2005). Ghost dialectics: Spirit photography in entertainment and belief. En: The Perfect Medium: Photography and the Occult. New Haven and London: Yale University Press, 46-71.

Comas Solà, J. (1907). El Espiritismo ante la ciencia: juicio crítico sobre la mediumnidad. [III]. La Publicidad, (68), 9-11.

Comas Solà, J (1908). El Espiritismo ante la ciencia. Barcelona: Atlante, 1908.

Corbetta, J. M. \& Savall, A. F. (2013). La fotografía espírita en la Argentina. En: Claudia Touris, C. y Contardo, M. F. (eds). Actas de las Terceras Jornadas de Religión y Sociedad en la Argentina Contemporánea y países del Cono Sur. Buenos Aires: RELIG-AR Ediciones. CDROM.

Corbetta, J. M. \& Savall, A. F. (2017). La fotografía espírita en la Argentina. EBoletín PSI [en línea], 12(2), [Consulta: 30 diciembre 2017]. Disponible en: $\quad$ http://www.alipsi.com.ar/e-boletin/E-BOLETINPSI_Vol.12_No2_Mayo_2017.html\#tito2>2.

Cruz, D. de la. (2017). To Which Earthly Categories Do Not Apply: Spirit Photography, Filipino Ghosts, and the Global Occult at the Turn of the Twentieth Century. Material Religion. The Journal of Objects, Art and Belief, 13(3). 301-328.

D. Ángel Grinda (1908). Luz y Unión, (12), 353-354.

España, M (1920). La hija de Conan Doyle. Mundo Gráfico, (18 febrero), 5 .

Esteva Marata, J. (1906a). Fotografías de espíritus. Luz y Unión, (6), 199-204.

Esteva Marata, J. (1906b). Fotografías. Luz y Unión, (7).

Fàbregas, P. (1874). Fotografía: remitido importante. Revista espiritista: Periódico de estudios psicológicos. (12), 282-283.

Fernández Colavida, J. M. (1874). La fotografía de los espíritus. Revista espiritista: Periódico de estudios psicológicos. (10), 226-230.

Fischer, A. (2005). "The Most Disreputable Camera in the World". Spirit Photography in the United Kingdom in the early twentieth century. En: The Perfect Medium: Photography and the Occult. New Haven and London: Yale University Press, 2005, 72-91.

Fischer A, y Loers V. (1997) Im Reich der Phantome, Fotografie des Unsichtbaren. Ostfildern: Cantz.

Fotografía espiritista. (1872). El Criterio espiritista, (8), 126-128.

Fotografía espiritista en Alicante. (1872a). La revelación: revista espiritista alicantina, (3), 30-31.

Fotografía espiritista en Alicante (1872b). El Criterio espiritista, (3), 42-43. 
Fontanella, L (1981). La historia de la fotografía en España desde sus orígenes hasta 1900. Madrid: El Viso.

Fotografía espiritista en Alicante (1872c). Revista espiritista: periódico de estudios psicológicos, (2), 44-45.

García Rodríguez, O. M. (2003). Orígenes del periodismo espirita en España. Flama Espirita, (109), 3-6.

García Felguera, M. de los S. (2008). Fotògrafes i científiques: Anna Atkins, Jessica Piazzi Smyth i Elizabeth Fleischmann”. En: Fotociència. Palma de Mallorca: Govern de les Illes Balears, 67-98.

Gettings, F. (1978). Ghosts in photographs: The extraordinary story of spirit photography. New York: Harmony Books.

Gómez Ros, F. (1914). Fragmento del libro Páginas íntimas de ultratumba. Comunicaciones, aportes y escrituras directas y fotografías espiritistas obtenidas por el Grupo María de Cartagena. Cartagena.

Grang, D. (1905). Una fotografía espiritista. Los albores de la verdad, 4-5.

Graus Ferrer, A. (2014) La ciencia del médium: Las investigaciones psíquicas en España (1888-1931) [Tesis doctoral inédita]. Cerdanyola del Vallès: Universitat Autònoma de Barcelona.

Guixà Frutos, R. (2009) La imagen trascendental. Fotografías de lo invisible. Fotografía y conocimiento en el siglo XIX. [Tesis doctoral inédita]. Barcelona: Universitat de Barcelona,

Gunning, T. (1995). Phantom images and modern manifestations. En: Petro, P. (ed.). Fugitive images : from photography to video. Bloomington: Indiana University Press, 1995, 42-71.

Gurney, E., William, F., Myers, H. \& Podmore, F. (1886). Phantasms of the living . London: Trübner and co., Ludgate Hill, E. C. 2 vol.

Hahin, L. (1930). Sir Arthur Cona Doyle. Heraldo de Madrid, (12 de julio), 7.

Harvey, J. (2007) Photography and Spirit. London: Reaktion Books.

Jolly, M. (2006). Faces of the living dead: The belief in spirit photography. London: The British Library.

K., L. (1872). Fotografía espiritista. La Revelación: Revista espiritista alicantina, (3), 29-30.

Kaplan, L. (2008). The Strange Case of William Mumler, Spirit Photographer. Minneapolis: University of Minnesota Press.

Kardec, A. (1863). Photographie des esprits. Revue Spirite, (3), 92-95.

Kardec, A. (1869). Un nuevo descubrimiento fotográfico. Revista espiritista: Periódico de estudios psicológicos, (7), 152-157.

[La maravilla de las maravillas] (1872). El Semanario Católico, (61), 137-138. 
Lestang, H (2017). Edouard Buguet. Portrait Sepia [en línea]. [Fecha de consulta: 30 diciembre 2017]. Disponible en: http://www.portraitsepia.fr/photographes/buguet.

Leymarie, P. G. (1874a). La photographie spirite. Revue Spirite, (2), 50-51.

Linares Albert, S. y Poveda Bernabé, R. (2014). Una colección de miradas. La fotografía en Alicante en el siglo XIX. Canelobre, (24), 501-513.

Leymarie, P. G. (1874b). La fotografía espiritista. El espiritismo, (4).

López Serrano, A. (1991). Prensa y periódicos en Yecla en el siglo XIX. Yakka: Revista de estudios yeclanos, (3), 23-58.

Martí Bonneval, F. (1875). Proceso de Buguet y Leymarie. El Espiritismo, (14), 419-421.

Mateos, A. (1873). La fotografía de lo invisible. Revista Espiritista. Periódico de estudios psicológicos, (11), 233-237.

Méndez Bejarano, M (1928). Historia de la filosofía en España: hasta el siglo $X X$. Madrid; Renacimiento.

Milner Garlitz, V. (2007). El centro del círculo: La lámpara maravillosa de Valle-Inclán. Santiago de Compostela: Servizo de Publicacións e Intercambio Científico da Universidade de Santiago de Compostela.

Monge López, J. M. (2015). Influencias literarias y filosóficas en La lámpara maravillosa de Ramón del Valle-inclán [Tesi doctoral inèdita]. Barcelona: Universitat Autònoma de Barcelona.

Ojeada retrospectiva al último bienio (1894). Revista de Estudios psicológicos, (1) $1-4$.

Otero Acevedo, M (1892). Fotografías pseudo espiritistas. La Ilustración Artística, (529), 103, 106, 112.

Ramos, V. (2004). Los orígenes polémicos del espiritismo en Alicante. Canelobre, (49), 218-235.

Rivera, Ilse W. de. (1936). El espiritismo y sus trucos. Ahora, (26 enero), 15-36.

Rodríguez Molina, M. J., Sanchís Alfonso, J. R. (2013). Directorio de fotógrafos en España (1851-1936): (elaborado con la información que proporcionan los anuarios y guías comerciales). Valencia: Archivo General y Fotográfico de la Diputación de Valencia. 2 vol.

Rousset-Guillot (1874). "Comment on devient médium photographe. Quelques preuves d'identité. Revue Spirite, (10).

Santoro Domingo, P. (2014). “iLevantaos, muertos de Verdún!” Una historia cultural del espiritismo tras la Gran Guerra. Sociología Histórica, (4), 289-321.

Torres Martinez, J. M. (1998). La Retina del sabio: un siglo de fotografía científica en Barcelona (1839-1936) [Tesis doctoral inédita]. Barcelona: Universitat de Barcelona. 
Violi, A. (2005). Lombroso e i fantasmi della scienza. Publif@rum [en línea], 2(1). [Fecha de consulta: 30 diciembre 2017]. Disponible en: http://www.farum.it/publifarumv/n/o1/violi.php

Winter, J. (1995). Sites of Memory, Sites of Mourning. The Great War in European Cultural History, Cambridge: Cambridge University Press. 